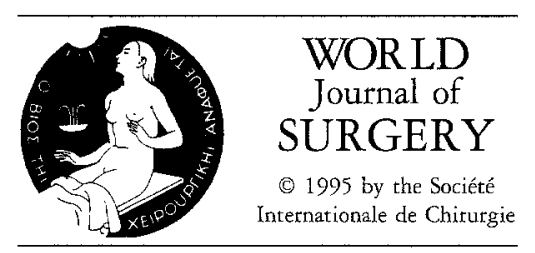

\title{
Survival after Resection of Gastric Cancer and Prognostic Relevance of Systematic Lymph Node Dissection: Twenty Years Experience in Taiwan
}

\author{
Wei-Jei Lee, M.D., ${ }^{1}$ Wen-Chung Lee, M.D., PhD. ${ }^{2}$ Shyh-Jinn Houng, M.D. ${ }^{1}$ Chia-Tung Shun, M.D. ${ }^{3}$ \\ Ren-Long Houng, M.D., ${ }^{4}$ Po-Hung Lee, M.D., ${ }^{1}$ King-Jen Chang, M.D., ${ }^{1}$ Ta-Cheng Wei, M.D., ${ }^{1}$ Kai-Mo Chen, M.D. ${ }^{1}$ \\ ${ }^{1}$ Department of Surgery, National Taiwan University Hospital, National Taiwan University, No. 7, Chung Shan South Road, Taipei, Taiwan, \\ Republic of China \\ ${ }^{2}$ Department of Public Health, National Taiwan University Hospital, National Taiwan University, No. 7, Chung Shan South Road, Taipei, \\ Taiwan, Republic of China \\ ${ }^{3}$ Department of Pathology, National Taiwan University Hospital, National Taiwan University, No. 7, Chung Shan South Road, Taipei, Taiwan, \\ Republic of China \\ ${ }^{4}$ Cancer Research Center, National Taiwan University Hospital, National Taiwan University, No. 7, Chung Shan South Road, Taipei, Taiwan, \\ Republic of China
}

\begin{abstract}
A retrospective study of 954 resectable gastric cancers in a single institute of Taiwan from 1971 to 1990 was performed to evaluate improvements in gastric cancer surgery. The patients were divided into four time periods representing an overall experience of progressive implementation of aggressive resection and increased extent of systematic lymph node dissection. The clinicopathologic data and survival rates were statistically compared and the significance of the extent of resection on survival analyzed. A significant increase in the proportion of upper one-third tumors (from $14.8 \%$ to $20.4 \%$ ) and a decrease in the incidence of intestinal type $(73.6 \%$ to $41.5 \%)$ was found within the overall period. The proportion of patients with early gastric cancer increased from $11.5 \%$ to $19.4 \%$. Patients who underwent total gastrectomy and combined visceral resection increased from $13.7 \%$ to $27.4 \%$ and $19.8 \%$ to $41.1 \%$, respectively. An increase of both total dissected lymph node number and the incidence of detected lymph node metastases in early gastric cancer were associated with more extensive lymphadenectomy. An improved 5-year survival rate following aggressive resection was found for all stages except stage $\mathrm{NV}$ and $\mathrm{T} 4$ lesions, and the surgical mortality decreased from $5.5 \%$ to $2.0 \%$. Patients with earlier stage lesions benefited more from radical resection, especially those with stage $I I$ and $T 2$ lesions. Systematic lymph node dissection increased the 5-year survival of patients by about $10 \%$ for stage III or T3 lesions but not for patients with stage IV or T4 lesions. Multivariate analysis confirmed the significance of the improved technique of lymphadenectomy on the prognosis of gastric cancer following resection in Taiwan. In conclusion, a changing pattern of gastric cancer epidemiology in Taiwan is documented. $A$ decrease in surgical mortality indicates that curative resection with extensive lymph node dissection can be safely performed. Although potential for increasing survival by upstaging remains, radical gastrectomy with extended lymphadenectomy could be adopted for gastric cancer resection with possibly more adequate control of locoregional disease.
\end{abstract}

Although gastric cancer is a major malignancy that occurs worldwide, its incidence varies geographically [1]. In Taiwan, gastric cancer remains the third leading cause of cancer death with

Correspondence to: K-M. Chen, M.D. annual death rates in 1990 of 15.4 and 7.2 deaths per 100,000 for males and females, respectively [2]. Surgery remains the primary therapeutic modality for gastric cancer. Although radical gastrectomy with systematic lymph node dissection has been advocated by both Japanese surgeons [3-6] and others [7, 8] as standard procedure for gastric cancer treatment, its status has not been characterized by prospective randomized trials $[9,10]$. In our hospital, an aggressive approach to lymph node dissection for gastric cancer has been used since the end of 1970 . Because of an encouraging initial experience, this approach was subsequently adopted as routine gastric cancer resection. It is not only interesting but of clinical importance to evaluate the overall result of gastric cancer surgery during the past 20 years when this aggressive program has been used. In this study, we focus on the survival rate following curative resection of gastric cancer for the period since the aggressive approach toward gastric cancer resection and lymphadenectomy was progressively implemented.

\section{Patients and Methods}

From 1 January 1971 through 31 December 1990 there were 954 patients who underwent gastric resections for primary adenocarcinoma of the stomach in the Department of Surgery, National Taiwan University. Patients' medical records were reviewed to ascertain age, sex, tumor location and size, and type of gastric resection. Survival status was determined from medical records and by personal follow-up. A detail histopathologic review of the pathologic slides were performed to determine the histologic type, depth of gastric wall invasion, number of lymph nodes excised, and the extent of lymph node metastases.

The classification and operation procedure was performed according to the protocol of the Japanese Research Society for 
Table 1. Clinicopathologic characteristics at different periods.

\begin{tabular}{|c|c|c|c|c|c|}
\hline Characteristic & $\begin{array}{l}1971-1975 \\
(n=182)\end{array}$ & $\begin{array}{l}1976-1980 \\
(n=249)\end{array}$ & $\begin{array}{l}1981-1985 \\
(n=224)\end{array}$ & $\begin{array}{l}1986-1990 \\
(n=299)\end{array}$ & $p$ \\
\hline Age (mean $\pm S D)$ & $59.4 \pm 11.9$ & $57.3 \pm 12.0$ & $58.8 \pm 12.0$ & $59.1 \pm 12.1$ & NS \\
\hline Male/female ratio & 2.6 & 2.3 & 1.8 & 2.0 & NS \\
\hline \multicolumn{6}{|l|}{ Location } \\
\hline Upper third & $27(14.8)$ & $36(14.5)$ & $46(20.5)$ & $61(20.4)$ & \multirow[t]{2}{*}{0.021} \\
\hline Middle third & $29(15.9)$ & $53(21.3)$ & $58(25.6)$ & $84(28.0)$ & \\
\hline \multicolumn{5}{|l|}{ Histology } & \multirow[t]{3}{*}{$<0.001$} \\
\hline Intestinal & $134(73.6)$ & $180(72.3)$ & $114(51.1)$ & $124(41.5)$ & \\
\hline Diffuse & $48(26.4)$ & $69(27.7)$ & $109(48.9)$ & $175(58.5)$ & \\
\hline \multicolumn{6}{|l|}{ Invasion depth } \\
\hline $\mathrm{T} 1$ & $21(11.5)$ & $39(15.7)$ & $32(14.3)$ & $58(19.4)$ & $<0.01$ \\
\hline $\mathrm{T} 2$ & $41(22.5)$ & $69(27.7)$ & $66(29.5)$ & $53(17.7)$ & NS \\
\hline
\end{tabular}

SD: standard deviation; NS: no significance; numbers in parentheses are percents.

Gastric Cancer (JRSGC) [11]. Nodal involvement is classified into $\mathrm{n}(-), \mathrm{n} 1(+), \mathrm{n} 2(+), \mathrm{n} 3(+)$, and $\mathrm{n} 4(+)$ according to the Japanese enumeration. The first three designations are similar to the pN0, $\mathrm{pN} 1$, and $\mathrm{pN} 2$ of the TNM system [12]. Both $\mathrm{n} 3(+)$ and $\mathrm{n} 4(+)$ are defined as metastasis, or pM1 in the TNM system. The extent of lymphadenectomy is classified as R1, R2, R3, and R4 according to the " $n$ " level for which lymph node dissection was performed. For cancer in the upper part, total gastrectomy with splenectomy and distal hemipancreatectomy was routinely performed as an R2 resection for clearance of associated lymph nodes. The histologic pattern was classified into intestinal and diffuse types on the basis of Lauren's classification [13].

The patients were grouped according to four periods: Period I (1971-1975) represented 182 patients on whom R1 resection was routinely performed. Period II (1976-1980) contained 249 patients on whom R1 or R2 resection was routinely performed. Period III (1981-1985) comprised 221 patients in whom R2 resection was routinely performed. Period IV (1986-1990) comprised 299 patients on whom R2 to R3 resection was the principal form of surgery. The depth of cancer invasion was defined according to the TNM system: pT1, the cancer has invaded the mucosa and submucosa; pT2, the tumor invaded the muscularis or the subserosa; pT3, the cancer invaded over the serosa; pT4, the cancer had invaded adjacent structures. The site of the cancer was classified into upper third (C), middle third (M), and lower third (A) of the stomach. The 5-year survival curves for the periods were compared and the results assessed with regard to differences in TNM stage, tumor location, and invasion depth of the cancer.

Survival curves were generated using the method of Kaplan and Meier. Statistical differences between survival curves were evaluated using the log-rank test. Differences between patient populations were assessed using the chi-square test, Kruskal-Wallis test, or ANOVA, as appropriate. Multivariate analysis with Cox's regression model was performed only for the most recent three periods because the data of the first period were not sufficiently detailed. Statistical analysis was done using the SAS package.

\section{Results}

\section{Clinicopathologic Background}

Clinicopathologic data were compared for patients of different time periods (Table 1). There were no differences in age distribution or sex ratio. Significant correlation was found between the location of tumors, distribution of invasion depth, and histologic type. A shift of gastric cancer from the distal third to upper third was observed during this period. Tumors of the upper third increased from $14.8 \%$ to $20.4 \%$, whereas the distal third localization decreased from $69.2 \%$ to $51.6 \%$. A shift in the intestinal type of gastric cancer was also observed to decrease from $73.6 \%$ to $41.5 \%$. Early gastric cancer increased from $11.5 \%$ to $19.4 \%$.

\section{Surgery}

There was a tendency to use the more extensive operation for resection of gastric cancer as time progressed (Table 2). More total gastrectomics and combined visceral resections were performed during the most recent period (1986-1990). Within this period, $27.4 \%$ of the patients underwent total gastrectomy and $41.1 \%$ underwent combined resection of other viscera. The average number of total dissected lymph nodes per patient increased throughout the study as well. During the first period (1971-1975) the average number of lymph nodes removed was $6.2 \pm 7.4$ compared to $32.3 \pm 16.7$ during the most recent period. This difference reflects the more aggressive approach taken with regard to lymphadenectomy during the latter portion of the study. Although more radical operations were performed within the most recent period, operative mortality decreased from $5.5 \%$ to $2.0 \%$. There was no increased incidence in the detection of lymph node metastases or in the number of metastases per patient over the various time periods. However, increased detection of nodal metastases was found for early cancer (T1) when stratified by the factor of invasion depth. 
Table 2. Pathologic characteristics at different periods.

\begin{tabular}{|c|c|c|c|c|c|}
\hline Characteristic & $\begin{array}{l}1971-1975 \\
(n=182)\end{array}$ & $\begin{array}{l}1976-1980 \\
(n=249)\end{array}$ & $\begin{array}{l}1981-1985 \\
(n=224)\end{array}$ & $\begin{array}{l}1986-1990 \\
(n=299)\end{array}$ & $p$ \\
\hline Curative resection & $131(72.0)$ & $221(88.8)$ & $192(86.8)$ & $239(79.9)$ & NS \\
\hline \multicolumn{6}{|l|}{ Extent of surgery } \\
\hline Total gastrectomy & $25(13.7)$ & $32(12.8)$ & $46(20.5)$ & $82(27.4)$ & $<0.001$ \\
\hline Total $\mathrm{LN}$ no. (mean $\pm \mathrm{SD})$ & $6.2 \pm 7.4$ & $11.5 \pm 10.2$ & $22.9 \pm 12.3$ & $32.3 \pm 16.7$ & $<0.001$ \\
\hline Combined resection & $36(19.8)$ & $68(27.3)$ & $81(36.2)$ & $123(41.1)$ & $<0.01$ \\
\hline Surgical mortality & $10(5.5)$ & $11(5.4)$ & $7(3.1)$ & $6(2.0)$ & \\
\hline \multicolumn{6}{|l|}{ LN metastases } \\
\hline All & $119(65.4)$ & $140(56.2)$ & $139(62.0)$ & $182(60.8)$ & NS \\
\hline Positive number & $3.4 \pm 6.2$ & $3.6 \pm 5.8$ & $4.8 \pm 7.8$ & $3.7 \pm 5.3$ & NS \\
\hline Related to depth & & & & & NS \\
\hline $\mathrm{T} 1$ & $2(4.7)$ & $3(7.7)$ & $4(12.5)$ & $9(15.5)$ & \\
\hline $\mathrm{T} 2$ & $20(48.8)$ & $25(36.2)$ & $33(50.0)$ & $25(47.2)$ & \\
\hline T3 & $80(79.2)$ & $102(79.7)$ & $94(81.0)$ & $121(75.6)$ & \\
\hline $\mathrm{T} 4$ & $17(89.5)$ & $10(76.9)$ & $8(80.0)$ & $27(96.4)$ & \\
\hline
\end{tabular}

LN: lymph node; SD: standard deviation; NS: no significance; numbers in parentheses are percents.

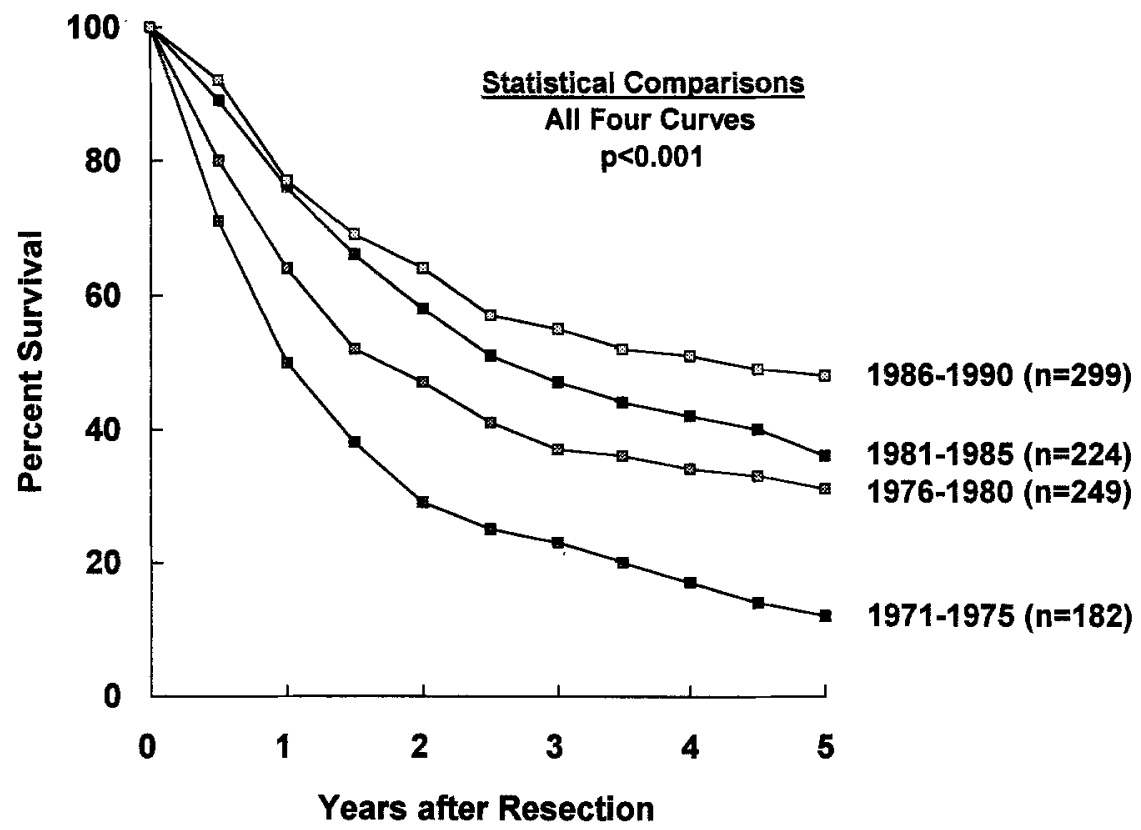

Fig. 1. Overall 5-year survival rate for various time periods: $24.7 \%$ in patients during 1971 $1975 ; 30.7 \%$ for patients during $1976-1980$; $36.8 \%$ for patients during 1981-1985; and $47.5 \%$ for patients during $1986-1990$.

Survival

Overall. Figure 1 shows the overall survival curves for the four time periods. A substantial increase in survival was observed within the overall span of 20 years. The cumulative 5-year survival rate of all resectable gastric cancer patients increased from $24.7 \%$ in period 1 to $47.5 \%$ in period 4 .

TNM Stage. The improved survival rates were observed for all stages except stage IV (Table 3). The 5-year survival rate increased from $72.2 \%$ to $93.3 \%$ in stage I and from $23.8 \%$ to $60.9 \%$ in stage II. However, the improvement in 5-year survival rate was rather limited in stage III patients (from $16.0 \%$ in period 1 to $24.8 \%$ in period 4 ). No increase of survival rate was achieved in the patients with stage IV disease throughout the study. During

the most recent period (1986-1990), the overall 5-year survival rate was $93.3 \%$ for stage I, $60.9 \%$ for stage II, $24.8 \%$ for stage III, and $4.8 \%$ for stage IV (Fig. 2). The 5-year survival rate in the subgroups was $100 \%$ for stage IA, $85.7 \%$ for stage IB, $48.1 \%$ for stage IIIA, $12.8 \%$ for stage IIIB, $12.5 \%$ for stage IV curative resection, and $0 \%$ 3-year survival for stage IV noncurative resection patients.

Invasiveness (T). For tumors of different invasion depth, signifcant improvement in 5-year survival was found for all $\mathrm{T}$ stages except T4. The improvement in 5-year survival was most significant for T2 tumors (31.7\% to $85.4 \%$ ) but was limited for T3 tumors $(12.9 \%$ to $21.4 \%)$. For $\mathrm{T} 1$ tumors the 5-year survival increased from $86.7 \%$ during period 1 to $98.3 \%$ during period 4 . 
Table 3. Cumulative 5-year survival rate for various time periods.

\begin{tabular}{|c|c|c|c|c|c|}
\hline Parameter & $\begin{array}{l}1971-1975 \\
(n=182)\end{array}$ & $\begin{array}{l}1976-1980 \\
(n=249)\end{array}$ & $\begin{array}{l}1981-1985 \\
(n=224)\end{array}$ & $\begin{array}{l}1986-1990 \\
(n=299)\end{array}$ & $p$ \\
\hline All patients & 24.7 & 30.7 & 36.8 & 47.5 & $<0.001$ \\
\hline Curative resection & 29.0 & 34.8 & 41.5 & 59.4 & $<0.001$ \\
\hline \multicolumn{6}{|l|}{ TNM stage } \\
\hline I & 72.2 & 68.3 & 79.5 & 93.3 & $<0.01$ \\
\hline II & 23.8 & 30.6 & 36.7 & 60.9 & $<0.05$ \\
\hline \multicolumn{6}{|l|}{ Invasion depth } \\
\hline $\mathrm{T} 1$ & 86.7 & 86.8 & 90.6 & 98.3 & $<0.05$ \\
\hline $\mathrm{T} 2$ & 30.6 & 31.1 & 49.6 & 85.4 & $<0.001$ \\
\hline T3 & 12.9 & 15.6 & 22.1 & 21.4 & $<0.01$ \\
\hline $\mathrm{T} 4$ & 12.0 & 7.7 & 10.0 & 10.0 & NS \\
\hline \multicolumn{6}{|l|}{ LN metastases } \\
\hline \multicolumn{6}{|l|}{ Tumor location } \\
\hline Upper & 13.3 & 5.7 & 19.5 & 20.6 & $<0.001$ \\
\hline Middle & 23.1 & 36.7 & 45.4 & 46.8 & NS \\
\hline Lower & 27.8 & 34.6 & 39.4 & 53.4 & $<0.05$ \\
\hline
\end{tabular}

LN: lymph node.

All values are percents.

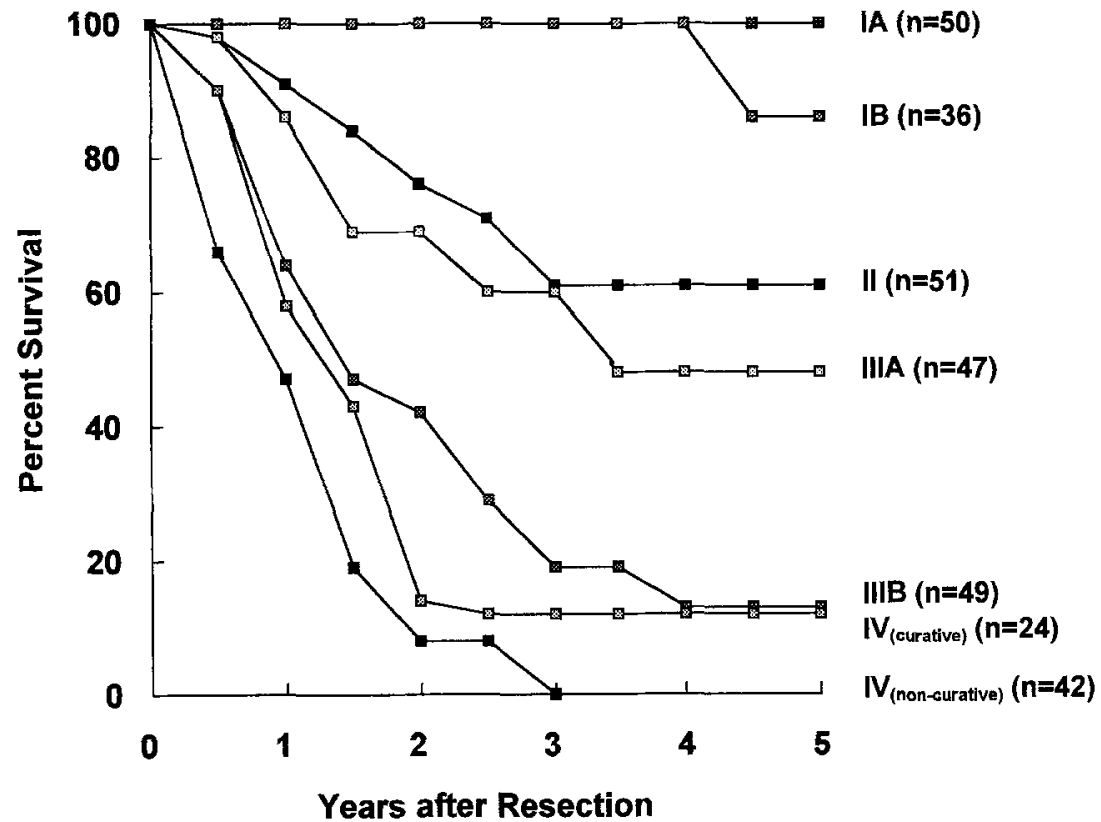

Fig. 2. Overall 5-year survival rate according to pathologic stage for patients during 1986-1990. It was $93.3 \%$ for stage I, $60.9 \%$ for stage II, $24.8 \%$ for stage III, and $4.8 \%$ for stage IV. The 5 -year survival rate in the subgroups was $100 \%$ for stage IA, $85.7 \%$ for stage IB, $48.1 \%$ for stage IIIA, $12.8 \%$ for stage IIIB, and $12.5 \%$ for stage IV curative resection. There were no 3 year survivals for stage IV noncurative resection patients.

Only one patient, with early gastric cancer of the cardia and lymph node metastases, died of the disease during the most recent period.

Lymph Node Number. An improvement in 5-year survival was found among patients with different numbers of lymph node metastases. Patients with limited node involvement (one to three nodes) were the most benefited group. The prognostic differences between patients with involvement of one to three and more than four nodes was significant during the most recent period but not during the earlier periods.
Tumor Site. For tumors of different locations, both distally and proximally located tumors showed significant increases in 5-year survival, but the prognosis is poorer for the proximally located tumor $(20.6 \%)$ compared to that for other areas. Although the 5 -year survival of patients with middle third tumors has increased, it is statistically insignificant.

Multivariate Analysis. Multivariate analysis using Cox's regression model with adjustment for various factors (including tumor location, histologic type, and type of gastrectomy) has confirmed that the progressive lymphadenectomy attitude had a significant 
Table 4. Hazard ratios of various periods according to the invasion depth of tumor.

\begin{tabular}{|c|c|c|c|}
\hline \multirow[b]{2}{*}{ Parameter } & \multicolumn{3}{|c|}{ Hazard ratios with $95 \%$ confidence intervals } \\
\hline & $\begin{array}{l}1976-1980 \\
(\mathrm{R} 1 / 2)^{a}\end{array}$ & $\begin{array}{l}1981-1985 \\
(\mathrm{R} 2)^{a}\end{array}$ & $\begin{array}{l}1986-1990 \\
(\mathrm{R} 2 / 3)^{a}\end{array}$ \\
\hline $\begin{array}{l}\text { Before adjustment, } \\
\text { all patients }\end{array}$ & 1.00 & $0.78(0.62-0.97)$ & $0.69(0.55-0.86)$ \\
\hline \multicolumn{4}{|l|}{ After adjustment ${ }^{b}$} \\
\hline All patients & 1.00 & $0.71(0.56-0.90)$ & $0.58(0.45-0.73)$ \\
\hline $\mathrm{T} 1$ and $\mathrm{T} 2$ & 1.00 & $0.68(0.44-1.05)$ & $0.19(0.10-0.38)$ \\
\hline $\mathrm{T} 3$ and $\mathrm{T} 4$ & 1.00 & $0.74(0.56-0.98)$ & $0.66(0.51-0.87)$ \\
\hline
\end{tabular}

${ }^{a}$ Extent of lymphadenectomy [11].

${ }^{b}$ Multivariate analysis using Cox's regression with the adjustment of tumor location, histologic type, and type of gastrectomy.

impact on the improved survival rate of gastric cancer patients following resection. In addition, the reduction of the hazard ratio is more significant for T1/T2 than T3/T4 tumors (Table 4).

\section{Discussion}

The age-adjusted mortality rate associated with gastric cancer decreased in Taiwan between 1970 and 1990 by $42 \%$ in men and $39 \%$ in women [2]. This finding corroborates the notable decline worldwide in gastric cancer mortality and incidence [14]. There has also been a recent trend toward a change in the site of origin of gastric carcinoma, with proximally located tumors becoming more prevalent [15-18]. For example, Cady et al. [17] reported that $34 \%$ of patients had proximal lesions in their 1989 series, compared to $20 \%$ in their 1945 series. Although the number of patients with resectable gastric cancer did not decrease in our series, our study indicates similar changes in the location and histologic type of gastric carcinoma. The rate of occurrence in proximally located tumors increased from $14.8 \%$ to $20.4 \%$ with a corresponding decrease in the rate of distally located tumors. The rate of intestinal-type gastric carcinomas decreased from $73.6 \%$ to $41.5 \%$, and a corresponding increase was found in the diffuse type. The rising relative incidence of proximally sited carcinoma highlights the rapid disappearance of distally located gastric cancers. Distally located cancers are "epidemic" in nature and are related to dietary variations, whereas the proximally located lesions are "endemic," diffuse-type in histology, and less related to dietary factors [19]. Other environmental factors, such as urbanization [2] and a decrease in Helicobacter pylori infection [20] may also contribute to this transition, as documented in Taiwan patients.

In the past, the surgical treatment of gastric cancer has varied mainly regarding the extent of resection. A frequent debate centers on whether radical lymph node dissection can improve the basically poor results of treatment with better survival. Recent studies from Japan suggested an improved survival of gastric cancer patients with an overall 5-year survival rate ranging between $40 \%$ and $50 \%$ following resection [3-6]. In contrast, however, the survival rate has not appreciably changed in Western countries, where the overall 5-year survival rate varies between $21 \%$ and $25 \%$ subsequent to resection $[15-18,21,22]$. Such differences have been attributed to the higher incidence of early cancer detection and the more aggressive surgical approach advocated by Japanese oncologists. To date, however, the suggested therapeutic effect of extended lymph node dissection has not been demonstrated in randomized trials $[9,10]$.
In this study, a substantial, significantly improved 5-year survival rate of resectable gastric cancer patients was documented in a single institute in Taiwan after a more aggressive approach toward gastric cancer resection and systematic lymphadenectomy was progressively implemented. Almost all TNM stages except stage IV were benefited from the extended lymph node dissection. However, the survival benefit is less than $10 \%$ in stage III patients. Because the evaluation of lymph node metastases and postoperative prognosis may be influenced by the extent of lymphadenectomy, which is known as "stage migration" or "Will Rogers phenomenon" [23], the comparison of the survival rates in different periods were conducted and stratified by $T$ stage as well as the conventional TNM staging. Significant improvements in prognosis were found for T1-T3 cancers but not for T4 cancers. Patients with a T2 lesion have the most dramatically increased 5-year survival: from $31 \%$ to $85 \%$. This group of patients was most benefited from radical lymphadenectomy, a fact confirmed by multivariate analysis. For those with a good prognosis and early gastric cancer (T1), radical lymph node dissection may detect more metastatic involvement and thus increase the completeness of surgical eradication of node metastases. Radical lymph node dissection revealed a $15.5 \%$ rate of lymph node metastases in early gastric cancer and almost $100 \%$ control of the disease in our study and others [24]. However, the benefit of lymphadenectomy for local control of gastric cancer was limited in their early stage. Once the cancer had invaded over the serosa (T3), the 5-year survival was $21.4 \%$ after radical lymphadenectomy, less than $10 \%$ increase compared with the $12.9 \%$ during the simple gastrectomy period. This phenomenon may be explained by the high incidence of N3 or N4 lymph node metastases [25], which were regarded as distant metastases and not curable by local treatment. Another explanation is the risk of intraperitoneal dissemination of the cancers that had invaded over the serosa [26]. For these patients, another treatment modality, such as neoadjuvant chemotherapy [27] or continuous hyperthermic peritoneal perfusion [28], should be used to improve the therapeutic advantage. In addition, the depressed cellular immunity found in advanced gastric cancer patients may play a significant role when electing treatment [29].

When the survival rate was compared in patients with different numbers of node metastases, those with limited involvement (fewer than four nodes involved), were most benefited by radical lymph node dissection. This effect may be due to the detection of nonominous micrometastases of gastric cancer by radical lymph node dissection-the effect of "stage migration" [30]. The fact that the survival of those with one to three involved nodes and those with more than three nodes involved was similar during the simple gastrectomy period but different during the radical lymphadenectomy period implies that the prognostic relevance of node number may be true only with radical lymph dissection, when more accurate staging is attained.

The effect of extended lymphadenectomy on the 5-year survival of gastric carcinoma patients was also analyzed in relation to the primary site of the lesion. The prognosis was found to be poor with carcinoma of the upper third of the stomach, which is consistent with other reports [15-18]. Although improved 5-year survival was observed in all three locations subsequent to the institution of more radical operations, significant improvement was found for those in whom the location was limited to the upper and lower one-thirds of the stomach. The 5-year survivals of 
Table 5. Comparison of gastric cancer resection results recorded in the United States [22], Japan [5], and NTUH.

\begin{tabular}{|c|c|c|c|c|c|c|}
\hline Parameter & \multicolumn{3}{|c|}{ Incidence $(\%)$} & \multicolumn{3}{|c|}{ Patients with resection: survival (\%) } \\
\hline No. of patients & 12,535 & 10,237 & 299 & & & \\
\hline Stage I & 33.7 & 17.1 & 29.0 & 95.6 & 50.0 & 93.3 \\
\hline Stage II & 14.5 & 16.9 & 16.7 & 70.1 & 29.0 & 60.9 \\
\hline Stage III & 28.7 & 35.5 & 32.0 & 36.3 & 13.0 & 24.8 \\
\hline Stage IV & 23.1 & 30.5 & 22.3 & 23.1 & 3.0 & 4.8 \\
\hline
\end{tabular}

patients in the most recent period were $20.6 \%, 46.8 \%$ and $53.4 \%$ for the upper, middle, and lower one-third, respectively.

Comparison with other large databases, such as those collected from Japanese and American hospitals, show some interesting trends (Table 5). The data from Japan have a high frequency of stage I gastric cancer (34\%) compared to the United States (17\%) and Taiwan (29\%), with fewer stage III and stage IV patients. The overall survival of patients with resection in the Japanese series was $56.3 \%$, similar to ours $(49.5 \%)$ but higher than the $19 \%$ in the United States. Not only is the stage more advanced in the U.S. series, but the 5-year survival is also considerably less according to stage. The 5-year survival rate in the United States was similar to our earliest period, when simple gastrectomy was routinely performed. Although comparisons between these retrospectively collected databases are not without problems, the large patient numbers do allow some inferences. Although complete resection of the primary tumor, dissection of lymph nodes, and more pathologic staging were performed in Japanese hospitals and ours, special education of the surgeon as a requisite for adequate gastrectomy may also factor into the increase in survival of patients with gastric cancer who undergo surgery. Our experience confirms recent reports that suggest curative resection with extensive lymphadenectomy can be safely performed without increasing, and perhaps even decreasing, surgical mortality [3-8]. The surgical mortality rates documented in the present study decreased from $5.5 \%$ during the $1970 \mathrm{~s}$ to $2.0 \%$ during the $1990 \mathrm{~s}$.

Although our experience confirmed the Japanese experience that radical resection could improve local control of gastric cancer and the survival rate [31], further improvement of the gastric cancer treatment results rely on the development of multimodality treatment. Radical resection provided almost $100 \%$ control of stage 1 disease, and no adjuvant therapy was needed. Stage II and IIIA patients had a relatively good prognosis following curative radical resection in our series, similar to the results of others [32]. Postoperative immunochemotherapy might further improve the survival rate as suggested in a recent report [33]. For stage IIIB and IV patients, surgery alone had no significant effect on improving long-term survival. Investigation of the application of neoadjuvant chemotherapy is warranted [27].

In summary, the present findings and our review of the literature suggests that extended lymph node dissection is valuable in the curative surgical treatment of stomach cancer. Radical gastrectomy with extensive lymphadenectomy can be safely performed without increasing surgical mortality, and it improves the prospect of cure for patients with this malignant disease.

\section{Résumé}

On a analysé rétrospectivement 954 patients ayant un cancer gastrique provenant d'un seul Hôpital de Taiwan entre 1971 et 1990 dans le but d'évaluer l'évolution du traitement. Les patients ont été étudiés selon quatre périodes correspondant à la pratique d'une résection de plus en plus agressive et d'un curage lymphatique de plus en plus étendu. Les données clinicopatholgiques et les taux de survie ont été analysés en fonction de l'étendue de la résection. On a constaté une augmentation de la proportion de tumeurs du tiers proximal (de $14.8 \%$ à $20.4 \%$ ) et une baisse des tumeurs du type intestinal (73.6\% à $41.5 \%)$. La proportion de patients ayant un cancer au début a augmenté de $11.5 \%$ à $19.4 \%$. Les patients ayant eu une gastrectomie totale seule ou combinée à une résection d'organe de voisinage a augmenté de $13.7 \%$ à $27.4 \%$ et de $19.8 \%$ à $41 \%$, respectivement. On a également constaté une augmentation du nombre total d'adénopathies enlevées et de l'incidence de métastases ganglionnaires détectées dans les cancers au début au fur et à mesure que l'étendue de la lymphadénectomie s'est développée. Une amélioration de la survie à 5 ans a été observée pour tous les stades de cancer exceptés ceux ayant une lésion T4 ou stade IV alors que la mortalité a diminué de $5.5 \%$ à $2.0 \%$ pendant ce même délai. Les patients qui ont tiré le plus de bénéfice du traitement radical étaient ceux qui avaient un cancer du stade II ou T2. La lymphadénectomie systématique augmente la survie d'environ $10 \%$ chez les patients du stade III ou T3, mais pas chez les patients du stade IV ou ayant une lésion T4. L'analyse multifactorielle a confirmé l'importance de la technique de dissection sur le pronostic du cancer gastrique dans cette population. En conclusion, on a documenté un changement épidémiologique du cancer gastrique à Taiwan. La baisse de mortalité indique que l'on peut effectuer une chirurgie radicale avec sécurité. Bien qu'il semble possible d'améliorer d'avantage la survie par 'upstaging' le stade, la gastrectomie radicale avec lymphadénectomie étendue pourrait être adaptée pour donner un contrôle satisfaisant de la maladie régionale.

\section{Resumen}

Se realizó un estudio retrospectivo de 954 pacientes con cáncer resecable del estómago en una única institución de Taiwan entre 1971 y 1990 , con el fin de determinar la mejoría en los resultados de la cirugía por cáncer gástrico. Los pacientes fueron divididos en 4 períodos que representaban la experiencia en la implementación progresiva de la técnica de resección radical y linfadenectomía sistemática extensa. Se hizo un análisis estadístico compara- 
tivo de los datos clínico-patológicos y del efecto de la radicalidad de la resección sobre la tasa de sobrevida. En el período de estudio se encontró un incremento significativo en la proporción de los tumores del tercio superior (de $14.8 \%$ a $20.4 \%$ ), disminución en la incidencia del carcinoma de tipo intestinal $(73.6 \%$ a $41.5 \%$ ) y ascenso del cáncer gástrico temprano (precoz) de $11.5 \%$ a $19.4 \%$. La proporción de pacientes sometidos a gastrectomía total y resección visceral combinada ascendió de $13.7 \%$ a $27.4 \%$ y de $19.8 \%$ a $41.1 \%$, respectivamente. Tanto el aumento en el número total de ganglios linfáticos disecados como en la incidencia de metástasis ganglionares detectadas en los pacientes con cáncer gástrico temprano apareció asociado con una linfadenectomía más extensa. Se halló mejoría en la tasa de sobrevida a cinco años luego de resección agresiva en todos los estadíos, excepto el estadío IV y lesión T4, en tanto que la mortalidad quirúrgica descendió de 5.5.\% a 3.0\%. Los pacientes en estadíos tempranos se beneficiaron más de la resección radical, especialmente aquellos en estadío II y lesiones T2. La disección ganglionar sistemática podría incrementar la tasa de sobrevida a cinco años en los pacientes en estadío III o con lesiones T3 en cerca de $10 \%$, pero no así en los pacientes en estadío IV o con lesiones T4. El análisis multivariable confirmó la significancia de las mejores técnicas de linfadenectomía sobre el pronóstico del cáncer gástrico luego de resección, en Taiwan. En conclusión, se ha demostrado un patrón cambiante de la epidemiología del cáncer de estómago en Taiwan; la disminución en la mortalidad quirúrgica indica que la resección curativa con disección gànglionar extensa puede ser realizada con buen margen de seguridad, aunque se acepta la posibilidad de la "upstaging". la gastrectomía radical con linfadenectomía extensa puede ser adoptada en la resección del cáncer del estómago para lograr un posible mejor control de la enfermedad local-regional.

\section{Acknowledgments}

This work was supported by grants from the National Science Council (NSC 83-0412-B-002-176) of Taiwan.

\section{References}

1. Correa, P.: The epidemiology of gastric cancer. World J. Surg. 15:228, 1991

2. Lee, W.C., Lin, R.S.: Interactions between birth-cohort and urbanization on gastric cancer mortality in Taiwan. Int. J. Epidemiol. 23:252, 1994

3. Kodoma, Y., Sugimachi, K., Matsusaka, T.: Evaluation of extensive lymph node dissection for carcinoma of the stomach. World J. Surg. 5:241, 1981

4. Sóga, J., Ohyama, S.I., Miyashita, K., Suzuki, T., Nashimoto A., Tanaka, O.: A statistical evaluation of advancement in gastric cancer surgery with special reference to the significance of lymphadenectomy for cure. World J. Surg. 12:398, 1988

5. Maruyama, K., Okabayashi, K., Kinoshita, T.: Progress in gastric cancer surgery in Japan and its limits of radicality. World J. Surg. $11: 418,1987$

6. Noguchi, Y., Imada, T., Matsumoto, A., Coit, D.G., Brennan, M.F.: Radical surgery for gastric cancer: a review of the Japanese experience. Cancer 64:2053, 1989

7. Shui, M.H., Moore, E., Sanders, M., et al.: Influence of the extent of resection on survival after curative treatment of gastric carcinoma. Arch. Surg. 122:1347, 1987

8. Jaehne, J., Myer, H.J., Maschek, H., et al.: Lymphadenectomy in gastric carcinoma: a prospective and prognosis study. Arch. Surg. 127:290, 1992
9. Dent, D.M., Madden, M.V., Price, S.K.: Randomized comparision of R1 and R2 gastrectomy for gastric carcinoma. Br. J. Surg. 75:110, 1988

10. Gilbertsen, V.A.: Results of treatment of stomach cancer. Cancer 23:1305, 1969

11. Japanese Research Society for Gastric Cancer: The general rules for the gastric cancer study in surgery and pathology. Jpn. J. Surg. 11:127, 1981

12. Hermanek, P., Sobin, L.H., editors: TNM Classification of Malignant Tumors (4th ed.). Berlin, Springer-Verlag, 1987

13. Lauren, P.: The two histological main types of gastric carcinoma: diffuse and so called intestinal type carcinoma. Acta Pathol. Microbiol. Scand. 64:31, 1965

14. Howson, C.P., Hiyama, T., Wynder, E.L.: The decline in gastric cancer: epidemiology of an unplanned triumph. Epidemiol. Rev. 8:1, 1986

15. Antonioli, D.A., Goldman, H.: Changes in the location and type of gastric adenocarcinoma. Cancer 50:775, 1982

16. Meyers, W., Damiano, R.J., Postlethwait, R.W., Rotolọ F.S.: Adenocarcinoma of the stomach: changing patterns over the last 4 decades. Ann. Surg. 205:1, 1987

17. Cady, B., Rossi, R.L., Silverman, M.L., Piccione, W., Heck, T.A.: Gastric adenocarcinoma: a disease in transition. Arch. Surg. 124:303, 1989

18. Breaux, J.R., Bringaze, W., Chappuis, C.: Adenocarcinoma of the stomach: a review of 35 years and 1710 cases. World J. Surg. 14:580, 1990

19. Correa, P.: Clinical implications of recent developments in gastric cancer: pathology and epidemiology. Semin. Oncol. 1:2, 1985

20. Lin, J.T., Wang, J.T., Wu, M.S., Lee, T.K. Chen, C.J.: Helicobacter pylori infection in a randomly selected population, healthy volunteers and patients with gastric ulcer and gastric adenocarcinoma: a seroprevalence study in Taiwan. Scand. J. Gastroenterol. 28:1067, 1993

21. Allum, W.H., Powell, D.J., McConkey, C.C., Fielding J.W.L.: Gastric cancer: a 25-year review. Br. J. Surg. 76:535, 1989

22. Wanebo, H.J., Kennedy, B.J., Chimel, J., Steele, G., Winchester, D. Osteen, R.: Cancer of the stomach: a patient care study by the American College of Surgeons. Ann. Surg. 18:583, 1993

23. Lee, W.J.: Prognostic relevance of systemic lymph node dissection in gastric carcinoma [letter]. Br. J. Surg. 81:315, 1994

24. Okamura, T., Tsujitani, S., Korenaga, D., Haraguchi, M., Baba, H., Hiramoto, Y.: Lymphadenectomy for cure in patients with early cancer and lymph node metastasis. Am. J. Surg. 155:476, 1988

25. Lee, W.J., Lee, P.H., Yue, S.C., Chang, K.J., Wei, T.C., Chen, K.M. Lymph node metastases in gastric cancer: significance of positive number. Oncology 52:45, 1995

26. Boku, T., Nakane, Y., Minoura, T.: Prognostic significance of serosa invasion and free intraperitoneal cancer cells in gaastric cancer. Br. J. Surg. 77:436, 1990

27. Lerner, A. Gonin, R. Steele, G.D., Mayer R.J.: Etoposide, doxorubicin, and cisplatin chemotherapy for advanced gastric adenocarcinoma: results of a phase II trial. J. Clin. Oncol. 10:536, 1992

28. Koga, S., Hamazoe, R., Maeta, M., Shimizu N., Murakami, A., Wakatsuki, T.: Prophylactic therapy for peritoneal recurrence of gastric cancer by continuous hyperthermic peritoneal perfusion. Cancer $61: 232,1988$

29. Lee, W.J., Chang, K.J., Lee, C.S., Chen, K.M.: Selective depression of T-lymphocyte subsets in gastric cancer patients: an implication of immunotherapy. J. Surg. Oncol. 55:165, 1994

30. Gunvén, P., Maruyama, K., Okabayashi, K., Sasaka, M., Kinoshita, T.: Nonominous micrometastases of gastric cancer. Br. J. Surg. 78:352, 1991

31. Nio, Y., Tsubono, M., Kawabata, K.: Comparison of survival curves of gastric cancer patients after surgery according to the UICC stage classification and the general rules for gastric cancer study by the Japanese Research Society for Gastric Cancer. Ann. Surg. 218:47, 1993

32. Siewart, J.R., Boottcher, K., Roder, J.D., Busch, R., Hermanek, P., Meyer, H.J.: Prognostic relevance of systematic lymph node dissection in gastric carcinoma. Br. J. Surg. 80:1015, 1993

33. Nakazato, H., Koike, A., Saji, S., Ogawa, N., Sakamoto, J.: Efficacy of immunochemotherapy as adjuvant treatment after curative resection of gastric cancer. Lancet 343:1122, 1994 